\title{
EFFICACY OF DISINFECTANTS AGAINST GRAM-POSITIVE BACTERIA FOUND ON THERMOPLASTIC RETAINERS
}

\author{
NADA ISMAH*, MIESJE K. PURWANEGARA, TUTI RAHMAWATI \\ Department of Orthodontics, Faculty of Dentistry, Universitas Indonesia, Jakarta 10430, Indonesia. E-mail: nadalukman@yahoo.com
} Received 30 September 2018, Revised and Accepted 22 February 2019

\section{ABSTRACT}

Objective: The present study aimed to compare the efficacy of two disinfectants against Gram-positive bacteria, particularly Streptococcus mutans, for use as a disinfectant for dental retainers.

Methods: In total, 35 thermoplastic retainers in this study were categorized into three immersion groups: control group; mouthwash group, using chlorhexidine $0.1 \%$; and denture cleanser tablet group. The retainers were worn for 15 days, and Gram-positive bacteria were enumerated before and after the retainers were immersed.

Results: We found a significant difference in bacterial numbers between the two disinfectant groups and the non-disinfectant or control group. Both disinfectant groups had decreased numbers of Gram-positive bacteria.

Conclusions: Disinfectant use is effective in decreasing the load of Gram-positive bacteria on thermoplastic retainers.

Keywords: Disinfectant, Disinfection, Thermoplastic retainer, Gram-positive bacteria, Streptococcus mutans.

(C) 2019 The Authors. Published by Innovare Academic Sciences Pvt Ltd. This is an open access article under the CC BY license (http://creativecommons. org/licenses/by/4. 0/) DOI: http://dx.doi.org/10.22159/ijap.2019.v11s1.180

\section{INTRODUCTION}

The retention phase is the final phase of orthodontic treatment, which aims to maintain the achieved esthetic and functional alignment of teeth [1]. The stabilization of teeth during the retention phase is obtained using an orthodontic device known as a retainer. Singh et al. showed that the most popular retainers for the maxilla and mandible are thermoplastic retainers [2]. Essix (Dentsply) is one of the most well-known brands that was first introduced in $1993[3,4]$.

Many orthodontists recommend that a retainer is used by the patient for a long time, perhaps for the rest of the patient's life [2,5-8]. Using an orthodontic device results in the accumulation of microorganisms, leading to biofilm formation, which may cause white spot, caries, and gingivitis $[9,10]$. Low et al. demonstrated that a bacterial colony had already developed on the surface of a thermoplastic orthodontic device after the first $6 \mathrm{~h}$ of use [11]. The bacteria largely comprised cocci. Bacterial load is directly proportional to the duration of retainer use [11]. Turkoz showed that a thermoplastic retainer is an ideal surface for the attachment of Streptococcus mutans and Lactobacillus bacteria. Lessa et al. studied bacterial contamination of removable orthodontic acrylic and showed that a retainer was gets contaminated by $S$. mutans, within a week of its use $[9,12]$. It is important to maintain the retainer and oral hygiene while using the retainer, to decrease the risk of poor oral hygiene.

Retainers may be cleaned mechanically, or chemically mechanical cleaning is achieved using a toothbrush (with or without toothpaste), whereas chemical cleaning is achieved through immersion into a disinfectant solution with an alcohol-based ingredient or using a denture cleanser with either alkaline hypochlorite or alkaline peroxide as the base ingredient [13-16]. The use of chlorhexidine as a disinfectant for acrylic retainers has been studied by Lessa et al. and Peixoto et al. In these studies, it was found that any decrease in $S$. mutans colonization was insignificant for the chlorhexidine group compared with the control group $[9,10]$. To date, no research has focused on the efficacy of disinfectants for thermoplastic retainer disinfection. Thus, we assessed the efficacy of two disinfectant groups against Gram-positive bacteria, particularly $S$. mutans, found on thermoplastic retainers. We used a denture disinfectant cleanser tablet solution (Polident) containing citric acid, sodium bicarbonate, sodium perborate, sodium polyphosphate, and potassium monopersulfate, and a mouthwash (Minosep) containing chlorhexidine digluconate $0.1 \%$ as the disinfectants to be tested. Aqua Dest distilled water was used as control.

\section{METHODS}

The present study entailed clinical and laboratory experiments that were conducted from February 2013 to May 2013. In total, 39 students of Faculty of Dentistry, University of Indonesia, participated in this study. The inclusion criteria were as follows: age 17-38 years; good general health; no malocclusion, no diastema and dental caries; no use of fixed or removable dentures; healthy periodontal condition (without visual inflammation); no antibiotic consumption for 2 weeks before sampling or during the study; and good oral hygiene (already scaling). Those with systemic disease history; those using antimicrobial mouthwash; smokers; and pregnant women were excluded from the study $[11-13,17]$. This study was approved by the Ethical Committee of Faculty of Dentistry, Universitas Indonesia, and informed consent was obtained from all the participants.

Block randomization was used to categorize the participants into three groups: Group A - using denture disinfectant tablet solution (Polident); Group B - using chlorhexidine 0.1\% mouthwash (Minosep); and Group C - using the control solution (Aqua Dest water). A maxillary impression was acquired, and a thermoplastic retainer (Essix type $\mathrm{C}+$ ) was fashioned for each subject, in accordance with the manufacturer's instructions. The participants were instructed to use the retainer for 15 days, removing it only while eating and drinking, and they were asked to rinse the retainer after eating before re-using it. The participants brushed their teeth in the morning and at night. The retainer was cleaned using a separate brush (provided by the researcher). The retainer was brushed without using toothpaste and in flowing water. The participants were asked to return on the first 
day after retainer insertion; on the second day, a swab sample of the retainer was collected before immersion. Further, based on the group to which the participant belonged, the retainer was immersed into the appropriate solution; the process of immersion was demonstrated to the participants as a guideline for immersion of the retainer at home. For Groups A and C, retainer immersion was performed once every day for 5 min. For Group B, retainer immersion was performed once every 4 days for $10 \mathrm{~min}$; on days 5,8 , and 11 , the participants were asked to return to the orthodontic clinic, and the retainers were immersed by a researcher. On other days, immersion was performed by the participants themselves. Participants were not permitted to use mouthwash during the study. On day 15, they returned to the orthodontic clinic, and a final swab sample of the retainer was collected after immersion; the duration of retainer use was considered to be complete at this stage.

The swab samples were used to enumerate the bacteria present in the biofilm that formed on the inner surface of the retainer. The cotton swabs were inserted into $500 \mu \mathrm{l}$ of phosphate-buffered saline in Microtubes. Each microtube was labeled and inserted into a cooling box to be transported to the Oral Biology Laboratory. Further, the contents of the tube were homogenized by vortexing for $\pm 10 \mathrm{~s}$. Using a micropipette, 25 $\mu \mathrm{l}$ of the solution was added to a TYSB2 0 agar plate. The plate was placed in an anaerobic jar and incubated at $37^{\circ}$ for 72 h. S. mutans colonies were manually enumerated. Data processing and statistical analysis were performed using SPSS software 17.0 (SPSS, Inc., Chicago, IL, USA).

\section{RESULTS}

Thirty-nine participants met the inclusion criteria, which resulted in 13 participants per treatment group. After final sample collection, 35 participants had processable data, with 11 in Group A, 12 in Group B, and 12 in Group C. the participants comprised 31 women and 4 men, aged of 17-31 (mean: 23.4) years. The efficacy of the disinfectants was determined in terms of the number of $S$. mutans colonies on TYSB20 agar before and after immersion. In total, 70 samples, collected from 35 participants, were categorized into three groups.

Intraobserver testing was performed using numerical two paired data test. Twelve subjects were taken from all the groups, include two calculation times, which are before and after treatment. Paired sample $\mathrm{t}$-test was used to analyze the data. Scores obtained from initial $(\mathrm{p}=1.00)$ and final calculation $(p=0.339)$ had $p>0.05$. There were no statistically significant differences between the groups in terms of intra-observer calculations.

Samples were acquired on the days 2 and 15 after retainer insertion. The data calculation was performed twice for each sample, and the mean score was calculated. Table 1 shows the $S$. mutans colony counts before and after immersion.

The normality of data distribution before and after treatment for each group resulted in $\mathrm{p}<0.05$; thus, the data distribution was not normal. Data pertaining to the numbers of bacteria on thermoplastic retainers before and after immersion were analyzed using two paired group numeric comparative analytic test. The Wilcoxon signed-rank test was used because of abnormal data distribution. The results for each group are shown in Table 2.

Based on this result, there was no significant difference in the numbers of bacteria on thermoplastic retainers before and after immersion for
Groups A and B. However, there a significant difference was noted before and after immersion for Group C.

Statistical analysis was performed to compare differences before and after treatment for each group. Data distribution found to be abnormal, so the Kruskal-Wallis test was used. That test resulted in $\mathrm{p}<0.05$, indicating a difference between the number of Gram-positive bacteria on thermoplastic retainers for disinfectants $\mathrm{A}$ and $\mathrm{B}$, and control solution C. Post hoc Mann-Whitney test was done.

$\mathrm{p}$ values for the intra-group test were $<0.05$, which was a statistically significant between Group C (control) and the disinfectant groups (A and B). Intra-group difference between Groups A and B had $p>0.05$; thus, the differences were not statistically significant.

\section{DISCUSSION}

The use of orthodontic devices increases the risk of poor oral hygiene. Whether a retainer is prepared from acrylic or thermoplastic, literature on the efficacy of retainer disinfectants is limited, despite plentiful recommendations about cleaning retainers. The most common cleaning method is brushing under flowing water, without the use of disinfectants. Possibly, this method is common because it is economically feasible and practical and yields adequate results.

In this study, the researchers completed training in the Oral Biology Laboratory in Faculty of Dentistry, Universitas Indonesia, under the supervision of experienced laboratory technician before the sampling procedure. The training includes the sampling method, preparation of instruments and materials, making the transport solution, making the agar media, the culture procedure, the determination of bacteria colony, the calculation of bacterial colonies, and storage of samples. In initial results, 39 subjects are included; however, the final data include 35 subjects, because one subject consumed antibiotics during the research, and three subjects did not follow the research procedure.

Bacterial colony characteristics were recorded. In addition, the measurement of bacteria colonies includes bacteria staining and observation under microscope with $\times 100$ magnification. The Grampositive bacteria appear purple and are a spherical (coccus) shape. The calculation of bacteria colonies is done manually by marking the bacteria on the agar base plate.

Intra-observer testing between the researcher and oral biology laboratory technician was performed by using nine samples for each measurement and the paired $t$-test for analysis; $p>0.05(p=0.487)$ and on final calculation $(p=0.924)$ showed no statistical significance in the differences in intra-observer measurements.

Disinfectant and control solutions were used to simulate the commonly used method of cleaning retainers under flowing water. One disinfectant is a mouthwash, which contains chlorhexidine digluconate, and is the most effective mouthwash compared to other mouthwashes [18]. The other disinfectant is the denture cleanser tablet, marketed by the Polident brand and already recommended as a cleaner for dentures and acrylic retainers.

The initial plan was to choose 39 participants and categorize them into three groups, each comprising 13 , with the anticipation of one dropping out of the study. The final count was 35 participants with 11 in Group A,

Table 1: Gram-positive bacterial colony-forming units on thermoplastic retainers

\begin{tabular}{|c|c|c|c|c|c|c|c|}
\hline \multirow[t]{2}{*}{ Group } & \multirow{2}{*}{$\begin{array}{l}\text { Subjects } \\
\text { number }\end{array}$} & \multicolumn{3}{|l|}{ Before } & \multicolumn{3}{|l|}{ After } \\
\hline & & $\begin{array}{l}\text { Minimum } \\
(40 \times \mathrm{cfu} / \mu \mathrm{L})\end{array}$ & $\begin{array}{l}\text { Maximum } \\
(40 \times \mathrm{cfu} / \mu \mathrm{L})\end{array}$ & $\begin{array}{l}\text { Median } \\
(40 \times c f u / \mu L)\end{array}$ & $\begin{array}{l}\text { Minimum } \\
(40 \times \mathrm{cfu} / \mu \mathrm{L})\end{array}$ & $\begin{array}{l}\text { Maximum } \\
(40 \times c f u / \mu L)\end{array}$ & $\begin{array}{l}\text { Median } \\
(40 \times c f u / \mu L)\end{array}$ \\
\hline A & 11 & 0 & 3904 & 83 & 2 & 887 & 123 \\
\hline B & 12 & 3 & 1620 & 240 & 0 & 2890 & 63 \\
\hline $\mathrm{C}$ & 12 & 0 & 1492 & 5 & 0 & 3587 & 144 \\
\hline
\end{tabular}


Table 2: Difference in the numbers of Gram-positive bacteria before and after immersion

\begin{tabular}{ll}
\hline Group & p-value before and after immersion \\
\hline A & 0.534 \\
B & 0.638 \\
C & 0.005 \\
\hline${ }^{*} \mathrm{p}<0.05$ &
\end{tabular}

Table 3: The intra-group post hoc results

\begin{tabular}{lll}
\hline Group & p score & Notes \\
\hline A - B & 0.951 & $\mathrm{p}>0.05$ \\
A - C & 0.023 & $\mathrm{p}<0.05^{*}$ \\
B -C & 0.038 & $\mathrm{p}<0.05^{*}$ \\
\hline
\end{tabular}

$* \mathrm{p}<0.05$

12 in Group B, and 12 in Group C. For each group to have a research power of $85 \%$, a minimum of 11 are needed in each group; thus, the groups are still within the normal range of research power of $80-95 \%$ [18].

Bacterial colony counts were abnormally distributed. This was caused by the subject choosing was not done based on certain colony count range, so many bacterial colony intra-subjects depended on individual physiologic condition. The initial intra-group data showed no statistically significant difference ( $p>0.05)$, so it was assumed that the intra-group bacterial colony count was the same. Because the participants were grouped randomly, the effects of confounding variables and the risk caused by exposure to other variables were equal for all the groups [18].

For the efficacy of disinfectants, a duration of 15 days was used as the interval before the final swabs and measurements. Low et al. stated that after initial $4-6 \mathrm{~h}$ of use, bacterial colonies begin to grow on a thermoplastic retainer, especially cocci, and the number of bacteria increases as the retainer usage increases. Those findings agree with the results of the present study. For the control group (C), the number of Gram-positive bacteria at the first and final swab was significantly different $(\mathrm{p}<0.05)$. However, for the disinfectant groups of chlorhexidine $0.1 \%$ and the denture cleanser tablet, there was no statistically significant difference in the number of bacteria during the time between the days 2 and 15 . That result shows that the accumulation of Gram-positive bacteria during the use of a retainer can be decreased by the using disinfectants. This meets the goal of disinfectant application, which is to decrease or remove pathogens [19].

To determine the most effective solution for retainer disinfection, a significant difference in the number of Gram-positive bacteria was seen between the control group and both disinfectant groups as shown in Table 3. This supports the findings of Lessa et al. and Peixoto et al. that used chlorhexidine mouthwash, and Da Silva et al. that used a denture cleanser tablet. However, the result contradict that of Shpack et al. which found no significant difference in the bacterial attachment on a thermoplastic retainer, with or without the use of chlorhexidine $[9,10,20,21]$. Chlorhexidine is widely used in various research studies, and it is considered to have good microorganism decontamination efficacy, not only for devices used inside the oral cavity, such as a toothbrush, acrylic denture, and acrylic retainer. Chlorhexidine is also used to clean cavities and root canals. Exposure to chlorhexidine causes the bacteria membrane cell wall to be ruptured, so there are cytoplasm leaks that cause cell death.

The result of thermoplastic retainer immersion with denture tablet cleanser also shows a statistically significant difference in Gram-positive bacteria counts when compared with the control group this was shown in Table 3. This agrees with research by Shpack et al. that supported the use of denture cleanser with a base ingredient of sodium sulfate (i.e., Invisalign Cleaning Crystals). The statistical significant different result was obtained compared to control group. However, the research result is contradicted with no statistically significant difference $[21,22]$. The denture cleanser tablet used in the present study has a combination of ingredients that provide a mechanical action to release the biofilm from the retainer surface, and a combination of various antimicrobial agents that damage the microorganism's cell wall.

A comparison of the chlorhexidine group and the denture tablet cleanser does not show a statistically significant difference in terms of efficacy it was shown at Table 3. da Silva et al. showed a significant difference between two disinfectant groups. They found chlorhexidine more effective when compared with denture cleanser tablet. That study used acrylic material in vitro with a larger sample size compared to the current study. Shpack et al. also showed different results. That study used Invisalign brand cleaning crystal tablets as immersion material and required shaking the retainer during immersion. This showed better results than chlorhexidine immersion. However, the cleaning tablet immersion accompanied by shaking was done with a different composition of cleaning tablet, which is a different clinical trial design $[20,21]$. Compared to using chlorhexidine, using a denture cleanser tablet adds additional cost to the effort of retainer cleaning. If following the usage instructions, the retainer should be immersed every day.

There are several subjects in Groups A and B who experienced a decrease in the number of Gram-positive bacteria on day fifteen. In Group B, seven of 12 subjects experienced a decrease of bacteria. In Group A, seven of 11 subjects had the same experience. All other subjects experienced an increase of bacteria. This was possibly caused by a difference in eating habits. The other possibility is the way the retainer was brushed and porosity of thermoplastic retainers. Although a thermoplastic retainer appears to be smooth, unlike the acrylic retainer, the edges of a thermoplastic retainer and the existence of micro gaps may become an attachment place for bacteria [23]. In the control group (12 subjects), there are no subjects who experienced a decrease in Gram-positive bacteria from days 5 to 15 . In this group, 11 subjects experienced an increase of bacteria, and one subject experienced no change. It is possible that subjects did not follow instructions for retainer usage and duration.

In a clinical trial, subjects, procedures, and results are blinded to prevent bias. The blinding is important, but not required. In this study, the design is single blinded. The disadvantage is the researcher may be aware of the kind of intervention that is being done, which can introduce treatment and measurement bias. A double-blind study design will eliminate most potential bias.

The selection of research subjects in this study was limited to dental students, who may not represent the target population in the community. The limitation of subjects was done to control the disinfectant process which was done in the orthodontic clinic. On this research, there is no subject choice procedure based on bacteria colony like in the research of Peixoto, et al., so the data distribution became abnormal. However, in this study, using the difference in the number of bacteria for all groups made it easier to assess the efficacy for different disinfectants. In a future study, another method can be used, including a larger sample size, choosing research subjects from different populations, and a different process of microbiology.

\section{CONCLUSIONS}

It can be concluded that a thermoplastic retainer cleaned in a disinfectant agent has a statistically significant difference in the number of Gram-positive bacteria colonies than retainers cleaned without disinfectant. Immersion of a thermoplastic retainer in a denture cleanser disinfectant agent once per day, or the immersion of a retainer in a chlorhexidine solution twice per week can maintain the bacteria colony count on relatively the same level. Using mouthwash with the core ingredient of chlorhexidine or a denture cleanser tablet will have the same efficacy for cleaning a thermoplastic retainer. 


\section{CONFLICTS OF INTERESTS}

The author reports no conflicts of interests.

\section{REFERENCES}

1. Graber TM, Vanarsdall RL, Vig KW. Orthodontics: Current Principles Techniques. Missouri: Mosby; 2000.

2. Singh P, Grammati S, Kirschen R. Orthodontic retention patterns in the United Kingdom. J Orthod 2009;36:115-21.

3. Tuncay OC. The Invisalign System. New Malden: Quintessance Publishing Co. Limited; 2006.

4. Kwon JS, Lee YK, Lim BS, Lim YK. Force delivery properties of thermoplastic orthodontic materials. Am J Orthod Dentofacial Orthop 2008;133:228-34.

5. Profitt WR, Fields HW Jr., Sarver D. Contemporary Orthodontics. Missouri: Mosby; 2007.

6. Pratt MC, Kluemper GT, Lindstrom AF. Patient compliance with orthodontic retainers in the postretention phase. Am J Orthod Dentofacial Orthop 2011;140:196-201.

7. Barlin S, Smith R, Reed R, Sandy J, Ireland AJ. A retrospective randomized double-blind comparison study of the effectiveness of hawley vs vacuum-formed retainers. Angle Orthod 2011;81:404-9.

8. Melrose C, Millett DT. Toward a perspective on orthodontic retention? Am J Orthod Dentofacial Orthop 1998;113:507-14.

9. Lessa FC, Enoki C, Ito IY, Faria G, Matsumoto MA, Nelson-Filho P, et al. In-vivo evaluation of the bacterial contamination and disinfection of acrylic baseplates of removable orthodontic appliances. Am J Orthod Dentofacial Orthop 2007;131:705.e11-7.

10. Peixoto IT, Enoki C, Ito IY, Matsumoto MA, Nelson-Filho P. Evaluation of home disinfection protocols for acrylic baseplates of removable orthodontic appliances: A randomized clinical investigation. Am J Orthod Dentofacial Orthop 2011;140:51-7.

11. Low B, Lee W, Seneviratne CJ, Samaranayake LP, Hägg U. Ultrastructure and morphology of biofilms on thermoplastic orthodontic appliances in 'fast' and 'slow' plaque formers. Eur J Orthod 2011;33:577-83.

12. Türköz C, Canigür Bavbek N, Kale Varlik S, Akça G. Influence of thermoplastic retainers on Streptococcus mutans and Lactobacillus adhesion. Am J Orthod Dentofacial Orthop 2012;141:598-603.

13. Gardner GD, Dunn WJ, Taloumis L. Wear comparison of thermoplastic materials used for orthodontic retainers. Am J Orthod Dentofacial Orthop 2003;124:294-7.

14. Ponitz RJ. Invisible retainers. Am J Orthod 1971;59:266-72.

15. Pascual AL, Beeman CS, Hicks EP, Bush HM, Mitchell RJ. The essential work of fracture of thermoplastic orthodontic retainer materials. Angle Orthod 2010;80:554-61.

16. White LW. How to achieve minor tooth movements with essix aligners. J Am Orthod Soc 2008;8:22-5.

17. Rody WJ Jr., Akhlaghi H, Akyalcin S, Wiltshire WA, Wijegunasinghe M, Filho GN, et al. Impact of orthodontic retainers on periodontal health status assessed by biomarkers in gingival crevicular fluid. Angle Orthod 2011;81:1083-9.

18. Sastroasmoro S. Dasar-Dasar Metodologi Penelitian Klinis. $4^{\text {th }}$ ed. Jakarta: Sagung Seto; 2011.

19. Centers for Disease Control and Prevention. Infection Prevention and Control Guidelines and Recommendations. Available from: http:// www.cdc.gov/oralhealth/infectioncontrol/guidelines. [Last accessed on 2012 Oct 08].

20. da Silva FC, Kimpara ET, Mancini MN, Balducci I, Jorge AO, KogaIto $\mathrm{CY}$, et al. Effectiveness of six different disinfectants on removing five microbial species and effects on the topographic characteristics of acrylic resin. J Prosthodont 2008;17:627-33.

21. Shpack N, Greenstein RB, Gazit D, Sarig R, Vardimon AD. Efficacy of three hygienic protocols in reducing biofilm adherence to removable thermoplastic appliance. Angle Orthod 2014;84:161-70.

22. Paranhos HF, Silva-Lovato CH, de Souza RF, Cruz PC, de FreitasPontes KM, Watanabe E, et al. Effect of three methods for cleaning dentures on biofilms formed in vitro on acrylic resin. J Prosthodont 2009; 18:427-31.

23. Pfeffer LA. Bacterial Adherence of Streptococcus mutans and Lactobacillus acidophillus on Poly-Methyl Methacrylate and Thermoplastic Polypropene Used in Orthodontic Retention. Las Vegas: Thesis Master of Oral Biology Department of Orthodontics, University of Nevada; 2011. 